\title{
Social implications for persons 5-10 years after spinal cord injury
}

\author{
F W A van Asbeck MD PhD, H Raadsen PT, M L J J van de Loo MD \\ Spinal Cord Injury Unit, 'De Hoogstraat' Rehabilitation Centre, Rembrandtkade 10, \\ NL-3583 TM Utrecht, The Netherlands.
}

\begin{abstract}
One hundred and seventy four persons with a spinal cord injury (SCI) were treated in the rehabilitation centre 'De Hoogstraat' in Utrecht, The Netherlands, between 1980 and 1985. One hundred and seventeen were available for a follow up study. Between 1990 and 1992 these 117 persons were visited and interviewed at home by a physiotherapist who worked in this centre, in order to find possible shortcomings in their rehabilitation programme and to advise accordingly on improvements. From this research project the following subjects are reported: housing, work/household, sport/hobbies, and marital status. The findings are described and compared with the literature.
\end{abstract}

Keywords: spinal cord injury; housing; employment; sport; marriage.

\section{Introduction}

After several years of rehabilitating patients with SCI in this centre, it appeared to be appropriate to carry out a systematic evaluation to ascertain the current status of our ex-patients compared with the data found in the literature, and to detect problems that could have been prevented. We were specially interested to discover if there were any systematic shortcomings in our rehabilitation programme.

\section{Material and methods}

The research was carried out between 1990 and 1992 on the expatients with a SCI, who were rehabilitated between 1980 and 1985 . Out of the 174 persons in this group (66 tetraplegics and 108 paraplegics) 117 (52 tetraplegics and 65 paraplegics) were available for investigation. The other 57 patients were not available for study because: they had died (23); their address was unknown (19); they were unwilling to cooperate (9); they had moved overseas (4); they had dementia (2).

Subjects were visited and interviewed at home by a physiotherapist who formerly worked in this centre. A semi-structured interview schedule was used, assessing the level of social functioning and the independ- ence for activities of daily living. In addition, an inventory was made of the complaints that existed in all the fields in which rehabilitation had taken place.

Age at the time of injury and sex of the 117 responding subjects are shown in Table I.

The level and completeness of their lesion, defined according to the lowest neurologically intact segment, is presented in Table II.

Thirteen of the 24 patients with an incomplete tetraplegia and 10 of the 15 patients with an incomplete paraplegia had some useful motor function in the lower extremities. The other 94 persons in the study were completely wheelchair bound.

The cause of the SCI was traumatic in 48 of the 52 tetraplegics and in 45 of the 65 paraplegics. The other causes were transverse myelitis, benign tumour, postoperative or unknown.

\section{Results}

Housing

In The Netherlands a SCI patient has the choice between adapting his house or moving to a more easily adaptable house, a 'Focus' house, a 'woonvorm', or a nursing home.

The costs of adaptations are subsidised by 
Table I Age at injury and sex of the study subjects

\begin{tabular}{|c|c|c|c|c|c|c|}
\hline \multirow[t]{2}{*}{ Age } & \multicolumn{2}{|c|}{ Tetraplegic } & \multicolumn{2}{|c|}{ Paraplegic } & \multicolumn{2}{|c|}{ Total } \\
\hline & $\mathbf{M}$ & $\mathrm{F}$ & $\mathbf{M}$ & $\mathrm{F}$ & $\mathbf{M}$ & $\mathrm{F}$ \\
\hline $18-20$ & 7 & - & 5 & 3 & 12 & 3 \\
\hline $21-30$ & 19 & 4 & 14 & 3 & 33 & 7 \\
\hline $31-40$ & 10 & 2 & 15 & 3 & 25 & 5 \\
\hline $41-50$ & 2 & 2 & 6 & 1 & 8 & 3 \\
\hline $51-60$ & 2 & 1 & 2 & 7 & 4 & 8 \\
\hline$>60$ & 2 & 1 & 1 & 5 & 3 & 6 \\
\hline Total & 42 & 10 & 43 & 22 & 85 & 32 \\
\hline
\end{tabular}

Table II Level and completeness of lesion

\begin{tabular}{lcrcccc}
\hline & $\mathrm{C} 4-\mathrm{C} 5$ & $\mathrm{C} 6$ & $\mathrm{C} 7-\mathrm{C} 8$ & $\mathrm{~T} 1-\mathrm{T} 12$ & $\mathrm{~L}$ & Total \\
\cline { 3 - 7 } Complete & 12 & 5 & 11 & 47 & 3 & 78 \\
Incomplete & 13 & 9 & 2 & 11 & 4 & 39 \\
Total & 25 & 16 & 13 & 58 & 7 & 117 \\
\hline
\end{tabular}

the local government to an equivalent of US\$1000-\$25.000 and in exceptional cases sometimes higher. The costs of moving to another house that can be more easily adapted are subsidised up to an equivalent of US\$ 1700 .

A Focus house is a privately rented adapted house or flat, built by the Focus Foundation among other houses to promote integration. These houses or flats are situated in clusters of 15-20 with a unit where help with the activities of daily living (ADL) can be obtained by intercom. The ADL help comes on request only and is available up to a maximum of 30 hours a week.

When neither of these options is possible, SCI patients have to be institutionalised in a 'woonvorm' or a nursing home. A 'woonvorm' is a centre for the physically handicapped, where they have an adapted private room, paid for through the social security system. These centres are not built among other houses. Help with ADL comes usually at fixed times although exceptions are possible, and this help is not limited to 30 hours a week.

The housing status of our study subjects is given in Table III.
Twenty-eight complaints about the housing situation were reported of which six could have been prevented by the rehabilitation team advising on other adaptations.

Work

The results from our study on work are given in Table IV.

Six of the 16 tetraplegics and four of the 22 paraplegics who were employed had some useful motor function in the lower limbs, the others being wheelchair bound.

Twelve of the 38 people who were employed had the same job as before their injury.

Twenty of these 38 people worked $32-40$ hours a week, five worked $>40$ hours and 13 worked $<32$ hours.

Twenty-eight people had a complaint about their working situation, which could have been prevented in one patient by the rehabilitation team making a better preparation for application interviews.

\section{Sport and hobbies}

Sport is an obligatory part of our rehabilitation programme. In this evaluation 48 
Table III Housing status of the study subjects

\begin{tabular}{lccc}
\hline & Tetraplegic & Paraplegic & Total \\
\hline Own/rented house & 41 & 64 & 105 \\
Focus house & 3 & 1 & 4 \\
Independent & 5 & & $109(93 \%)$ \\
Woonvorm & 3 & & \\
Nursing home & & & $8 \quad(7 \%)$ \\
Dependent & & & \\
\hline
\end{tabular}

Table IV Employment status in this study

\begin{tabular}{lcccc}
\hline & Tetraplegic & Paraplegic & Total & $(\%)$ \\
\hline Employed & 16 & 22 & 38 & $(32.4)$ \\
Study/training & 3 & 3 & 6 & $(5.1)$ \\
Household & 12 & 31 & 43 & $(36.7)$ \\
Voluntary work & 3 & 7 & 10 & $(8.5)$ \\
Retired & 3 & 2 & 3 & $(14.5)$ \\
Unemployed & 15 & 2 & 17 & $(14.5)$ \\
\hline
\end{tabular}

(41\%) (14 tetraplegics, 34 paraplegics) were still active in sport. Basketball was played by 11 , table tennis by nine, wheelchair racing by eight, tennis by four and other sports by nine persons.

Two complaints could have been prevented by the rehabilitation team. One patient was given wrong advice about a wheelchair, and another did not have information about the possibility of the sport of wheelchair racing.

In our study $101(86.3 \%)$ had at least one hobby. No complaints about these hobbies were reported.

\section{Marital status}

Data on marital status are presented in Table V. 'Married' in this table also includes people who live together but are not married.

Of the 67 people who were married both before and after the injury six had a different marriage partner.

Of the $21(6+15)$ who were divorced or separated after injury six reported that the divorce was not a result of the injury.

Twenty-six respondents reported problems with personal relationships resulting from the injury. They all said that the

Table V Marital status

\begin{tabular}{|c|c|c|c|c|}
\hline \multirow[t]{2}{*}{ Before injury } & & & \multicolumn{2}{|c|}{ After injury } \\
\hline & & & Married & Not married \\
\hline \multirow[t]{3}{*}{ Married } & Tetraplegic & 27 & 21 & 6 \\
\hline & Paraplegic & 55 & 46 & 9 \\
\hline & Total & 82 & $67(82 \%)$ & $15(18 \%)$ \\
\hline \multirow[t]{2}{*}{ Not married } & $\begin{array}{l}\text { Tetraplegic } \\
\text { Paraplegic }\end{array}$ & $\begin{array}{l}25 \\
10\end{array}$ & $\begin{array}{r}11 \\
2\end{array}$ & $\begin{array}{r}14 \\
8\end{array}$ \\
\hline & Total & 35 & $13(37 \%)$ & $22(63 \%)$ \\
\hline
\end{tabular}


rehabilitation team could at its best prepare them for and advise on these problems, but that prevention was not possible.

\section{Discussion}

\section{Housing}

Housing status after SCI has been reported by several authors ${ }^{1-4}$ from different countries. Sutton ${ }^{1}$ reported on the situation of patients rehabilitated in Hexham, England, Richards $^{2}$ on patients from Brisbane, Australia, Creek et $a l^{3}$ on patients from Aylesbury, England and Yarkony et al ${ }^{4}$ on patients from Chicago, USA. Their results are reported in Table VI.

Although these figures come from different countries with differences in the structure of housing provision and help systems for activities of daily living, it is the only source with which to compare our own figures.

It is interesting to note that the $93 \%$ of our respondents who live independently does not differ much from the percentages found in literature.

Since our Focus appartments have become more available nowadays we expect to reduce our number of institutionalised patients in the near future still further.
Work

Employment status of SCI persons has been investigated by several authors..$^{2,5-7}$ Their results are given in Table VII.

These authors reported from different countries where employment possibilities and unemployment benefits differ from those in The Netherlands. Only one author ${ }^{6}$ gives the level of preinjury training.

Three authors ${ }^{5-7}$ do not mention the retired group. Richards ${ }^{5}$ does not mention ages. DeVivo ${ }^{6}$ has patients from 13-59 years of age with probably no retired persons. Nakajima ${ }^{7}$ has patients from 16 to 73 with $38 \%>50$ years, so in his group there might be some retired persons. Unfortunately Nakajima ${ }^{7}$ does not give figures on the activities of the unemployed, although he mentions that some male patients had to keep house while their wives worked.

This lack of data on activities makes it difficult to compare our data with the literature. In spite of this it is interesting that the percentage of people engaged in gainful employment in our study $(32.4 \%)$ does not differ much from the trends in these publications.

The percentage of unemployed in our study $(17 \%)$ seems to be low compared with this literature but this might be due to the relatively high percentage of people that

Table VI Housing status in SCI

\begin{tabular}{|c|c|c|c|}
\hline Author & (Adapted) house & Institution & Total \\
\hline Sutton et $a l^{1}$ & $62(98 \%)$ & $1(2 \%)$ & 63 \\
\hline Richards $^{2}$ & $156(94 \%)$ & $10(6 \%)$ & 166 \\
\hline Creek et $a l^{3}$ & $65(84 \%)$ & $12(16 \%)$ & 77 \\
\hline Yarkony et $a^{4}$ & $1285(93 \%)$ & $97(7 \%)$ & 1382 \\
\hline
\end{tabular}

Table VII Employment status of SCI persons

\begin{tabular}{lrccccc}
\hline Author & Employed & $\begin{array}{c}\text { Study/ } \\
\text { training }\end{array}$ & $\begin{array}{c}\text { Managing } \\
\text { household }\end{array}$ & Retired & Unemployed & Total \\
\hline Richards $^{2}$ & $46(29 \%)$ & $14(7 \%)$ & $7(4 \%)$ & $8(5 \%)$ & $86(53 \%)$ & 161 \\
Richards $^{5}$ & $23(23 \%)$ & $14(14 \%)$ & $15(15 \%)$ & - & $48(48 \%)$ & 100 \\
DeVivo et al $^{6}$ & $46(30 \%)$ & $16(10 \%)$ & $13(8 \%)$ & - & $79(51 \%)$ & 154 \\
Nakajima \& Honda & $271(28 \%)$ & - & - & - & - & 926 \\
\hline
\end{tabular}


Table VIII Marital status (married includes living together)

\begin{tabular}{|c|c|c|c|}
\hline \multirow[t]{2}{*}{ Author } & \multirow{2}{*}{$\begin{array}{l}\text { Before } \\
\text { injury }\end{array}$} & \multicolumn{2}{|c|}{ After injury } \\
\hline & & Married (M) & Not married (NM) \\
\hline \multirow[t]{2}{*}{ Sutton et al ${ }^{1}$} & M 39 & $33(85 \%)$ & $6(15 \%)$ \\
\hline & NM 36 & $2(6 \%)$ & $34(94 \%)$ \\
\hline \multirow[t]{2}{*}{ Creek et $a l^{3}$} & M 26 & $20(77 \%)$ & $6(23 \%)$ \\
\hline & NM 51 & $?$ & ? \\
\hline \multirow[t]{2}{*}{ Guttmann ${ }^{9}$} & M 689 & $632(92 \%)$ & $57 \quad(8 \%)$ \\
\hline & NM 816 & $302(37 \%)$ & $514(63 \%)$ \\
\hline \multirow[t]{2}{*}{ Deyoe $^{10}$} & M 101 & $75(74 \%)$ & $26(26 \%)$ \\
\hline & NM 118 & $71(60 \%)$ & $47(30 \%)$ \\
\hline \multirow{2}{*}{ Crewe et al ${ }^{11}$} & M 35 & $24(69 \%)$ & $11(31 \%)$ \\
\hline & NM 93 & $31(33 \%)$ & $62(67 \%)$ \\
\hline \multirow[t]{2}{*}{ Pinkerton \& Griffin ${ }^{12}$} & M 9 & $5(55 \%)$ & $4(45 \%)$ \\
\hline & NM 15 & $2(13 \%)$ & $13(87 \%)$ \\
\hline
\end{tabular}

considers housekeeping their main occupation. In fact a large number of male paraplegics who might have been classified as unemployed look after the household.

\section{Sport/hobbies}

We found no data in the literature reporting the hobbies of SCI patients and only two reports concerning continued participation in sport after discharge.

Richards $^{2}$ reported that $33 \%$ of 166 SCI patients expressed frustration at being unable to pursue their favourite sport and had given up entirely. Curtis $e t a l^{8}$ reported on a group of 67 SCI patients of whom $72 \%$ were involved in sports like basketball, swimming, weightlifting, tennis, road racing and others at least once a week.

These figures do not allow us to make comparisons about the participation in sports of our SCI patients after discharge from the rehabilitation centre.

\section{Marital status}

Several authors ${ }^{1,3,9-12}$ reported on the marital status of SCI patients. Their results are given in Table VIII.

Our data of $82 \%$ married after injury more or less conforms to the average found in this literature. The other data vary so much that it is not clear whether our data confirm a trend.

\section{Complaints}

There were very few complaints from the patients, and this can be explained by the hypothesis that in 5-10 years the majority of people adjust to their social situation and do not complain any more about unsatisfactory situations. Further evaluations should possibly be done earlier after the rehabilitation period.

\section{Conclusions}

Study of the independent living, employment and postinjury marital status of our study subjects confirms the data found in the literature, in spite of the differences in housing provision and unemployment benefit systems. Other aspects could not be compared due to the insufficient data found in the literature.

The investigation of the complaints revealed by this study showed that there were no systematic shortcomings in the rehabilitation programme.

\section{References}

1 Sutton RA, Bentley M, Castree B, Mattison R, Pattison J, Smith R (1982) Review of the social situation of paraplegic and tetraplegic patients rehabilitated in the Hexham Regional Spinal Injury Unit in the north of England over the past four years. Paraplegia 20: 71-79. 
2 Richards B (1982) A social and psychological study of 166 spinal cord injured patients from Queensland. Paraplegia 20: 90-96.

3 Creek G, Moore M, Olivier M, Salisbury V, Silver J, Zarb G (1988) Personal and social implications of spinal cord injury: a retrospective study. Thames Polytechnic, Avery Hill Campus, London: 110, 239.

4 Yarkony GM, Roth EJ, Meyer PR, Lovell L, Heinemann AW, Bets HB (1990) Spinal cord injury care system: fifteen-year experience at the Rehabilitation Institute of Chicago. Paraplegia 28: 321-329.

5 Richards B (1975) An evaluation of home care after spinal cord injury. Paraplegia 12: 263-267.

6 DeVivo MJ, Richard DR, Stover SL, Fine PR (1987) Employment after spinal cord injury. Arch Phys Med Rehabil 68: 494-498.

7 Nakajima A, Honda S (1988) Physical and social condition of rehabilitated spinal cord injury patients in Japan: a long-term review. Paraplegia 26: 165-176.

8 Curtis KA. McClanahan S, Hail KM, Dillon D, Brown KF (1986) Health, vocational and functional status in spinal cord injured athletes and nonathletes. Arch Phys Med Rehabil 67: 862-865.

9 Guttmann L (1964) The married lives of paraplegics and tetraplegics. Paraplegia 10: 219-224.

10 Deyoe FS (1972) Marriage and family patterns with long-term spinal cord injury. Paraplegia 10: $219-224$.

11 Crewe NM, Athelstan GT, Krumberger J (1979) Spinal cord injury: comparison of preinjury and postinjury marriages. Arch Phys Med Rehabil 60: 252-256.

12 Pinkerton AC, Griffin ML (1983) Rehabilitation outcomes in females with spinal cord injury: a follow-up study. Paraplegia 21: 166-175. 